University of Nebraska - Lincoln

DigitalCommons@University of Nebraska - Lincoln

1989

\title{
Toward a Resolution of the Paradox of Aggressive Displays: I. Optimal Deceit in the Communication of Fighting Ability
}

\author{
Alan B. Bond \\ University of Nebraska - Lincoln, abond1@unl.edu
}

Follow this and additional works at: https://digitalcommons.unl.edu/bioscibehavior

Part of the Behavior and Ethology Commons

Bond, Alan B., "Toward a Resolution of the Paradox of Aggressive Displays: I. Optimal Deceit in the Communication of Fighting Ability" (1989). Papers in Behavior and Biological Sciences. 56.

https://digitalcommons.unl.edu/bioscibehavior/56

This Article is brought to you for free and open access by the Papers in the Biological Sciences at DigitalCommons@University of Nebraska - Lincoln. It has been accepted for inclusion in Papers in Behavior and Biological Sciences by an authorized administrator of DigitalCommons@University of Nebraska - Lincoln. 


\title{
Toward a Resolution of the Paradox of Aggressive Displays: I. Optimal Deceit in the Communication of Fighting Ability
}

\author{
Alan B. BOND \\ With 6 figures
}

Received: December 30, 1987

Accepted: August S, 1988 (G. Barlow)

\begin{abstract}
One inference from game theory models of animal conflict is that adversaries should not inform one another about concealed components of their fighting ability. This poses a paradox for the customary ethological account of aggressive displays in that it is usually assumed that the primary function of such behavior is to make such information available. To resolve the paradox, I propose that the information in aggressive displays may not be strictly truthful, but may instead represent "optimal deceit," a balance between the advantages of deceit or bluffing and the disadvantages of selecting for skepticism in the receiver. Numerical simulation of this model was performed to examine the effects of differences in fighting ability and in the risk of injury in an escalated conflict. The model converged on an equilibrium level of deceit, even when the receiver was ignorant of the average level of deception being employed.
\end{abstract}

\section{Introduction}

Fighting that can result in serious injuries does occur during animal conflicts (GEIST 1974). One of the principal insights of classical ethology, however, was that it does not invariably occur. Many animal conflicts appear to be resolved solely on the basis of aggressive displays. Display has, thus, customarily been viewed as a substitute for combat, an alternative and less hazardous means of assessing aggressive superiority (TINBERGEN 1951).

Accordingly, conflict resolution by display and by fighting should yield similar outcomes. An individual that would have been defeated in actual combat should not generally be able to win through display alone. Displays must, therefore, provide a truthful rendering of aggressive attributes, in that they must be roughly predictive of the animal's performance in actual combat. Thus, the 
central function of aggressive display, in the customary view, is the affordance of information about the aggressive capabilities and dispositions of the displaying individual. In SMITH's (1977) words, displays are "acts specialized to make information available."

Some of the information provided by displays, such as an animal's sex or size, may be implicit in the physical appearance of the displaying individual. DAWKINS \& KREBS (1978) have pointed out that aggressive displays often constitute feats of strength, agility, or endurance and may, therefore, also provide information about these attributes. Success in aggressive interactions often depends on other, less conspicuous factors, however, such as an individual's prior experience, its social status, its current level of arousal, its willingness to persist in combat, or the level of injury it is capable of sustaining.

Such experiential or dispositional attributes are not commonly exhibited directly in the performance of a display. In many animals, however, the relevant information seems to be encoded in the form and frequency of display behavior. The remarkable diversity of aggressive displays, in contrast to the small number of behaviorial events involved in nonagonistic interactions (ANDERSSON 1980), strongly suggests a diversity in meanings related to concealed attributes. This inference is supported by the fact that different aggressive displays are commonly seen to be associated with differing degrees of likelihood of attack or withdrawal in the contest (TINBERGEN 1959; HINDE 1981). The complex of displays thus provides a "graded signal" of aggressive intensity, a concept with a respectable history in the ethological literature (SMITH 1977).

These customary interpretations of aggressive display have recently been strongly disputed by a group of theorists concerned with the evolution of display behavior. The argument was orginally developed by MAYNARD SMITH (1972, 1974). He conceptualized animal conflict as a two-person game in which each participant chooses among a number of possible strategies. The strategies vary in their potential fitness costs from low-risk alternatives, involving only display behavior, to "escalated" fighting that entails actual physical combat. The choices are presumed to be made on the basis of their expected net fitness payoffs. Each individual, in this perspective, is seen as attempting to maximize its access to resources and minimize its risk of injurious combat by manipulating the information available to its opponent.

The game formalism divides the attributes of the participants into two groupings: those that contribute to an underlying difference in relative fighting ability ("resource holding potential" in PARKER's [1974] terminology) that would determine the outcome if the interaction were to be escalated; and those that reflect the individual's choice of strategy (its motivation or aggressive "intentions"). Through similar but independent lines of argument addressed to each of these groupings, game theorists have concluded that there is no selective pressure favoring truthfulness in aggressive displays with respect to either fighting ability or motivation.

The argument concerned with fighting ability, which is the central focus of this paper, will be referred to as "the Natural Superiority of Deceit." It has been advanced, apparently independently, by a number of different authors (DAwKINS 
\& Krebs 1978; Maynard Smith \& Parker 1976; Caryl 1979; Zahavi 1977). The argument asserts that truthful communication about capability, if its veracity is not compelled by physical appearance or implicit in the difficulty of the display, is open to unlimited exploitation by deceitful individuals.

Their reasoning is as follows. If the mere appearance of aggressiveness will significantly increase the probability of winning, then all individuals should adopt an aggressive appearance, without regard to their true capabilities. Selection will, therefore, drive the system to a state in which all individuals invariably display the maximum degree of aggressiveness, at which point the display becomes effectively meaningless. Note that this argument does not assert that noninformative displars are necessarily deceptive (MrTCHELL 1986), but that a continuous selection for misleading displays will eventually render them noninformative. The conclusion has been that whenever independent confirmation of an animal's ability is lacking, natural selection will inevitably assure a noninformative display.

The game theoretic argument thus poses a serious paradox for the customary account of animal aggression. If the function of aggressive displays is to influence or manipulate the behavior of one's opponent, they must not provide truthful information about concealed abilities. If displays do not provide truthful information, they will evolve to a uniform expression of maximum intensity. Since such behavior is uninformative of the capabilities of the signaller, the display will be ignored by the receiver and fail to influence its behavior. The only reliable information about an opponent's invisible aggressive attributes, therefore, is obtained by challenging him to combat, and this essentially obviates the presumed adaptive significance of display. The result is a paradox: if displays are not truthful, they cannot have been selected for; if they were selected for communication, they cannot be truthful.

The response of many ethologists has simply been to deny the paradoxical conclusion. They argue that graded signals do occur and are sufficiently predictive of the future behavior of the displaying animal, provided that one correctly interprets the conditional and probabilistic nature of the message (HINDE 1981; SMITH 1986; Barlow \& Rowell 1984; van Rhijn 1980). Hence, displays do, in fact, provide valid information about the displaying individual. The implication is that the paradox is some sort of artifact of the game theory approach or the result of overlooking additional factors, such as the occurrence of repeated encounters between individuals that can remember and recognize one another (VAN RHIJN 1980; VAN RHIJN \& VODEGEL 1980).

These arguments have considerable force, and they clearly indicate that the inference from the game theory models must be incorrect. This does not, however, fully address the source of the problem. The paradox owes nothing to game theory, as such. The theorists simply encountered it in the course of developing a rigorous account of the evolution of displays. If the inferences from this account are at variance with real-world observations, there must be an error in the underlying premises, in the assumptions involved in the customary view of animal conflict.

I believe that there are two crucial assumptions in the customary view that require modification to resolve the paradox: that graded displays present valid 
information about the internal state of the displaying animal and that the display of such information is, in fact, the central function of the behavior. In this paper, I will propose a modification of the first assumption, accepting a version of the Natural Superiority of Deceit. I will, however, argue that deceit is subject to stabilizing selection, and that it will not, in general, become fixed at maximum levels. In a companion article (BoND 1989), I will address the second assumption in the light of the arguments of the game theorists that the level of aggressive motivation ought not to be expressed in displays.

\section{The Argument for Optimal Deceit}

The argument of the Natural Superiority of Deceit derives from a consideration of the fitness payoffs for the displaying individual. It appears to ignore, however, the selective factors that operate on the receiver of misinformation. The possibility of "deceit," in the simple sense of a disparity between true and displayed capabilities (MrTCHELl 1986), may select against veracity, but it also selects strongly against credulity. In the absence of direct means of verification, there is always a selective advantage to a certain amount of healthy skepticism.

In a poker game, the bets of a persistent bluffer will eventually be ignored. His opponents will come to play against him only on the basis of prior probabilities, thereby elevating the likelihood that his bluff will be called by a player with a superior hand. In the long run, a persistent bluffer will lose. By analogy, it can be argued that any increment in deceit in a communication system will select for increased skepticism, thereby reducing the selective value of deceit. Deceit, by this reasoning, is subject to stabilizing selection, thereby preventing the postulated fixation of completely uninformative displays. Similar arguments have been proposed by ZAHAVI (1981), MoYNIHAN (1982), and SMITH (1986).

When the game model is extended to incorporate these features, it generates a novel perspective on the role of deceit in animal conflict. At least some of the time, a deceitful display will cause a rival to back down, when in fact he would have won in an escalated battle. There is, therefore, a selective disadvantage to absolute truthfulness. Extravagant or excessively frequent deceit will select for skepticism, however, and increase the likelihood that the veracity of the display will be tested by escalation. Since escalation is costly to both parties, wholly noninformative displays ought also to be selected against. The inference seems clear that there should be some optimal level of misinformation in displays that will provide the maximum degree of undeserved success while minimizing the cost of elicited escalations.

Most previous game theoretical models have assumed that each participant accurately assesses the other's fighting ability, presumably by means of displays that cannot readily be faked (PARKER 1974; HAMMERSTEIN 1981; MAYNARD SMITH 1982). When imperfect knowledge has been assumed, as with a number of extensions to MAYNARD SMITH's (1974) "war of attrition" model, the concern has been with the costs of verification through brief, probing episodes of active combat, rather than with variation in the information content of the display (Parker \& Rubenstein 1981; Hammerstein \& Parker 1982). The existing 
Fig. 1: Payoff matrix. Fighting ability for Signaller $=\mathrm{V}_{\mathrm{s}}$; fighting ability for Receiver $=V_{R}$. Signaller strategies and payoffs are shown in Roman type; Receiver strategies and

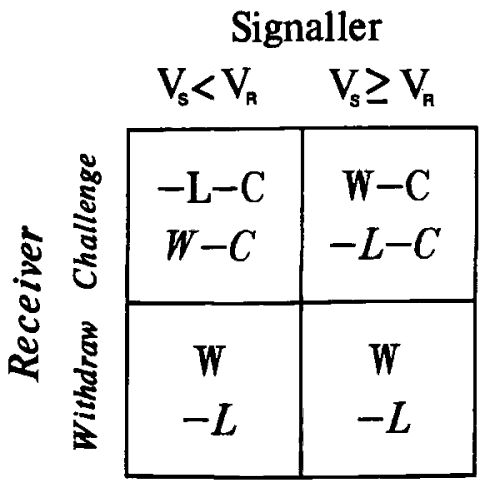
payoffs are in italics

literature on game theoretical analysis of aggression has not, therefore, addressed the possibility of "optimal deceit." To test this inference requires the development of a novel game formalism, one that includes the possibility of deceit as an explicit and central feature.

\section{The Rules of the Game}

We will begin by imagining an aggressive interaction between two individuals. We will assume that they have had no prior experience of one another, and that they are entirely evenly matched in apparent physical capabilities. The outcome of an escalated battle will, therefore, depend solely on concealed, internal factors, such as disposition and experience. We will represent these factors by a variable, $\mathrm{V}$, which we will call "fighting ability." In this model, V will be treated as an integer variable with values between 1 and 10 .

The focus of the model is a single transfer of information: the Signaller, who is assumed to be in possession of the resource in contention, generates a graded display that may be more or less indicative of his actual level of concealed fighting ability. The display, $\mathrm{V}^{*}$, is also represented as an integer between 1 and 10 . The Receiver must then make a decision, given a knowledge of his own fighting ability and the probable level of deceit being employed, whether to challenge the Signaller and escalate to full-scale combat or to withdraw. We will assume that, in the absence of any other information, the Receiver will treat all levels of $\mathrm{V}$ as being equally probable, which is to say that the a priori odds distribution is uniform.

The Receiver's decision is formulated on the basis of the payoff matrix in Fig. 1. If he withdraws, he loses some quantity, L, and the Signaller gains a quantity, $\mathrm{W}$, irrespective of their relative fighting ability. This corresponds to the Signaller's being left in possession of the resource, while the Receiver has to look for resources elsewhere. When the Receiver chooses to challenge, the winner is the individual with the higher level of $\mathrm{V}$; in case of ties, the decision goes to the Signaller. There is a cost to challenging, however: a factor, $C$, which corresponds to the risk of being injured in an escalated conflict, that is subtracted from the payoffs for both participants. Except for the cost factor, which renders this a non- 
zero-sum game, the model is formally equivalent to Liar's Poker, a contest based on the poker hands formed from the serial numbers on a dollar bill (I owe this insight to R. H. WILKINSON).

The only way the Receiver can win is to challenge when his fighting ability is higher, but losing on a challenge is more expensive than withdrawing. The Receiver's preferred strategy is, therefore, a function of the relative ability ranking: when he possesses a higher value of $\mathrm{V}$ than the Signaller, he should challenge; otherwise, he should withdraw. The behavior of the Receiver will, therefore, be strongly influenced by the amount of information that he can extract from the Signaller's display, and the Signaller is in a position to manipulate the Receiver's choice to his own advantage by altering the truthfulness of his display.

Even when the Signaller has a higher level of fighting ability, he should prefer to win by convincing the Receiver to withdraw, since winning on a withdrawal is more profitable than winning on a challenge. This implies that the Signaller should avoid concealing a high value of $\mathrm{V}$, since such behavior would only encourage the Receiver to challenge him, thereby reducing the magnitude of the Signaller's reward. The only rational form of deception in this game, therefore, is exaggeration. The success of an exaggeration strategy depends critically on the credulity of the Receiver, however. If the displays of the Signaller come to bear too little relationship to reality, the Receiver will simply ignore them and play the game on the basis of the a priori odds.

\section{Three Simple Display Strategies}

The dynamics of this contest can be roughly illustrated by calculating the expected payoff for each participant that results from each of three simple display strategies: veracity, noninformation, and a deception strategy that results in a small, consistent probability that the Receiver will withdraw when he would have won an escalated interaction. The details of the computation are provided in Appendix A.

If the Signaller is always truthful, the Receiver will always withdraw when he would lose on a challenge and always challenge when his V level is higher; his expected payoff is at a maximum with this strategy. The Signaller can improve his expectation substantially, however, if he can, by means of bluff or exaggeration, dupe the Receiver into withdrawing more often. For a rough estimation, we will assume that $10 \%$ of the contests the Signaller would otherwise have lost might be turned to wins by exaggeration. The consequences of the third strategy, noninformation, will depend on the Receiver's evaluation of the a priori odds.

The relative effects of these three strategies can be visualized by evaluating the expected payoffs for Signaller and Receiver for specific values of the payoff parameters. To illustrate we assume $\mathrm{L}=\mathrm{W}=5$ and evaluate the payoff expectations for both participants for three levels of C: 0.3 (= Low Cost), 0.9 (= Medium Cost), and 3.0 (= High Cost) (Table 1).

Note that the $10 \%$-deceit strategy is preferable to either absolute veracity or noninformation at both low and medium levels of cost. Only at the high-cost level is the noninformative strategy preferred, and even then the preference only 
Table 1: Expected Payoffs for three simple strategies for different costs of challenging

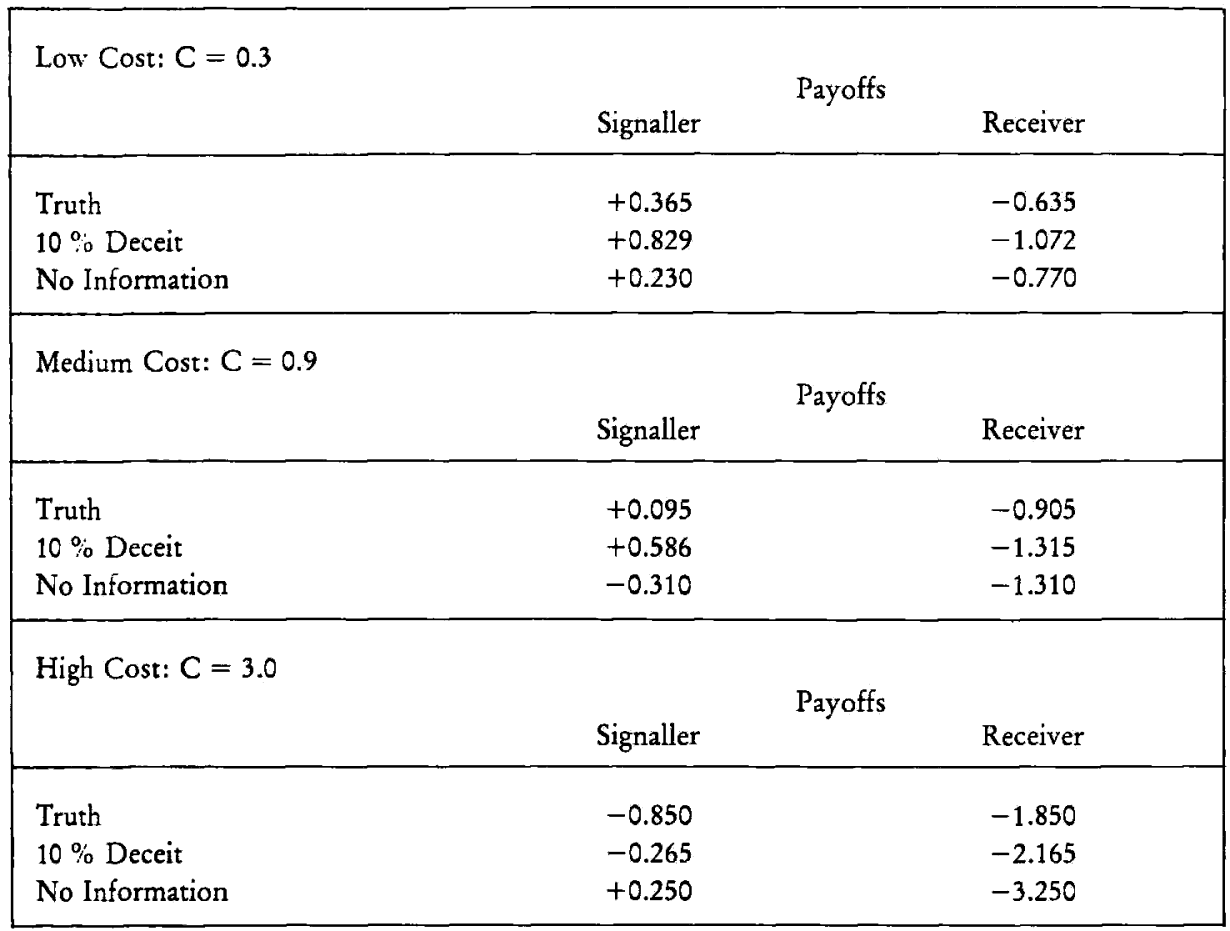

reflects the limited number of alternatives being considered. If the expected payoff had been computed for a $20 \%$, rather than a $10 \%$, success rate, deception would have been preferred to noninformation even under the high-cost condition. A numerical exploration of this model of aggressive communication thus appears likely to provide a reasonable evaluation of the hypothesis of optimal deceit.

\section{A Simulation of Deceitful Communication}

An effective bluffing strategy must contain a stochastic component; the Receiver must never be certain of just how much exaggeration is taking place. To simulate this feature of the model, I have assumed that the degree of overstatement is distributed as a Poisson variable. If the Signaller's fighting ability is $\mathrm{V}_{\mathrm{S}}$, the probability of a display of $\mathrm{V}^{*}$ is a function of the difference between the display and the true value. The generating parameter of the Poisson distribution, $\mathrm{x}$, represents the expected value of this disparity and will be termed the "exaggeration factor." Details of the algorithm are provided in Appendix B.

The behavior of this function corresponds well to what we would wish from a measure of deceit. When $x=0$, the Signaller always states the truth about his concealed abilities. As $\mathrm{x}$ increases, the probability converges to 1 of declaring V* $=10$, independently of the value of $V_{S}$, thereby providing no useful information to the Receiver. Since $\mathrm{x}$ is always positive in a Poisson distribution, the Signaller will never undervalue his own abilities: 


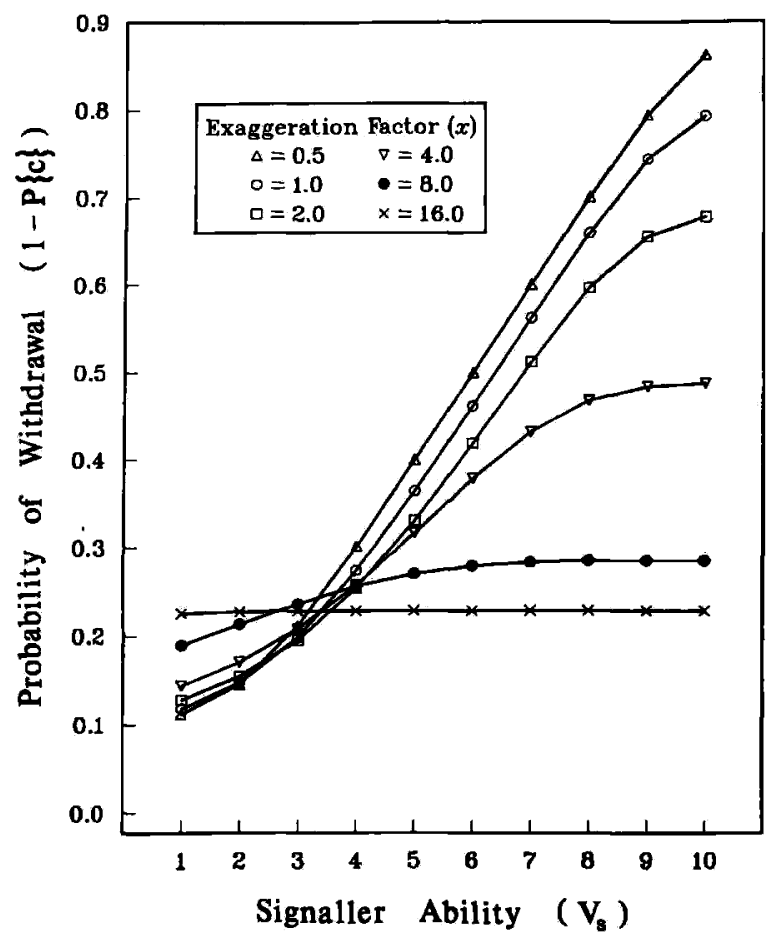

Fig. 2: Aggregate probability of the Receiver's withdrawal $(1-P\{c\})$ across all possible values of Signaller ability $\left(\mathrm{V}_{\mathrm{s}}\right)$ for six different levels of exaggeration factor (x). Payoff matrix used: $\mathrm{L}=5 ; \mathrm{W}=5$; $\mathrm{C}=0.9$

To model the response of the Receiver, we begin by assuming that he knows the exaggeration factor, $x$, being employed by the Signaller, as well as the value of $\mathrm{V} *$. From these two sources of information, the Receiver can construct a retrospective probability distribution for the true value of $V_{S}$. Given the retrospective distribution and a knowledge of his own fighting ability, $V_{R}$, the Receiver can then estimate the probability that the Signaller would win on a challenge. The Receiver can then use this probability, in combination with the payoff matrix, to determine his actions. (A full description of the decision algorithm is provided in Appendix B.)

The Receiver's behavior, thus, is essentially deterministic. Given the payoff matrix, the exaggeration factor, and the Signaller's display, the probability that the Receiver will challenge or withdraw is uniquely specified. Notice in Fig. 2 that for low exaggeration factors $(x=0.5$ or 1.0$)$, the Receiver places a great deal of credence in the Signaller's display, and the probability that the Receiver will withdraw increases almost linearly with the Signaller's fighting ability, $\mathrm{V}_{\mathrm{s}}$. As the exaggeration factor increases, the slope of the curve declines, indicating a reduction in the probability of withdrawal for higher values of $\mathrm{V}_{\mathrm{S}}$ and an increase in withdrawal probability for lower ones. For $x=16$, the curve is flat, indicating that there is virtually no information in the Signaller's display, and the Receiver challenges or withdraws entirely on the basis of prior probabilities. The behavior of the model system is, thus, much as was postulated in the introductory argument. 
Fig. 3: Plot of expected payoff to the Signaller $\left(E_{s}\right)$, as a function of exaggeration factor $(x)$, for each possible value of fighting ability $\left(V_{s}\right)$. Least extreme maxima are plotted as filled circles. A true optimum value was found for all values of $V_{5}$ between 3 to 9 . Payoff matrix used: $\mathrm{L}=5 ; \mathrm{W}=5 ; \mathrm{C}=0.9$

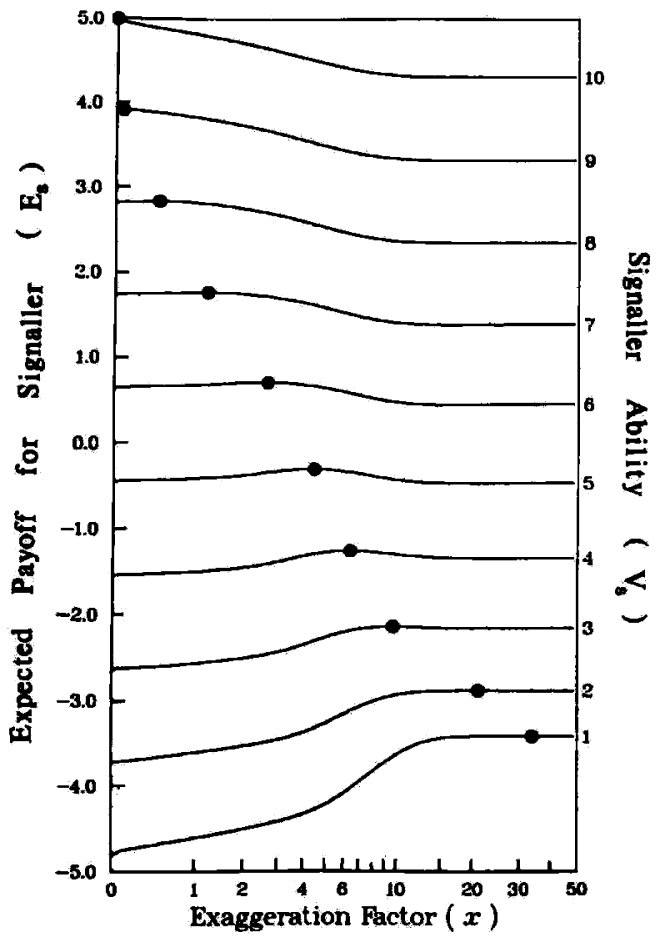

When the expected payoff is graphed as a function of exaggeration factor for each level of Signaller ability (Fig. 3), the optimum exaggeration factor, defined as the least extreme value that will produce the maximum payoff expectation, can be determined by a simple iterative search. Hence, the Signaller does best to employ the literal truth when his fighting ability is 10 and to exaggerate maximally with an ability of 1 or 2 . For $V_{S}$ values of from 3 to 9 , however, the payoff to the Signaller was optimized at an intermediate level of exaggeration, with clear decreases resulting from exaggeration factors above and below the optimum. The optimum exaggeration factor appears to be roughly a logarithmic function of $\mathrm{V}_{s}$, as is indicated by the scaling of the $\mathrm{x}$ axis in Fig. 3 .

The sensitivity of the optimum exaggeration level to the payoff matrix is displayed in Fig. 4. The behavior of the model is a function of the Receiver's decision, which, in turn, is a function of $V_{C}$, the Bayesian critical value of the Receiver's fighting ability. As shown in Appendix A, this value is a simple function of the cost of challenging, $C$, and the sum of basic win and loss payoffs, $(\mathrm{L}+\mathrm{W})$. It therefore appears that the full spectrum of effects of variation in payoff values can be displayed by setting $(L+W)$ to a constant value (arbitrarily, 10) and varying $C$ over the range $(0,10)$. The optimum exaggeration factor for each value of $V_{S}$ was computed for each payoff combination and plotted in Figure 4. The optimum exaggeration factor increased with $C$ for all values of $V_{S}$, but the slope of the function was reduced with increasing levels of Signaller ability. 


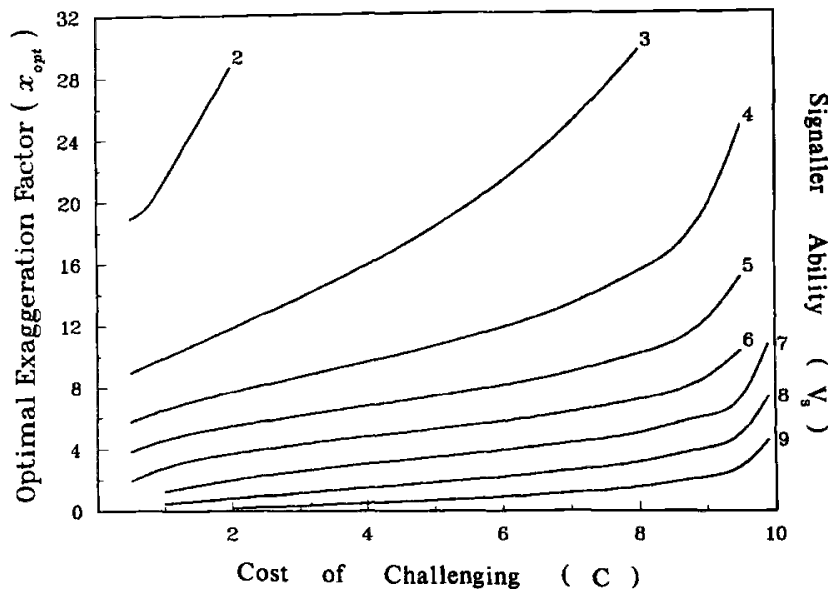

Fig. 4: Variation in optimal exaggeration factor $\left(\mathrm{x}_{\mathrm{opt}}\right)$ with cost of challenging (C) for each possible value of fighting ability $\left(V_{S}\right)$

\section{Optimization in the Absence of Complete Knowledge}

So far we have assumed that the exaggeration factor employed in generating the display was known beforehand to both parties. Although the Receiver did not know how much exaggeration was involved on any given occasion, he had a reliable knowledge of the average level. The Receiver's behavior thus involved a simple extrapolation from two known parameters. This assumption of complete knowledge of the underlying display strategy is unrealistic, however. To know that optimal deceit may be operating in the real world, we need to assess the stability of the communication system when the Receiver cannot be assured of the average level of exaggeration being employed.

The elimination of the constraint of complete knowledge requires creating two exaggeration factors, one for each participant. As before, the Signaller's factor, $x$, determines the relationship between $V_{S}$ and $V *$. The Receiver's exaggeration factor, $y$, represents the value that he believes the Signaller to be using; the Receiver's factor will then determine his retrospective probability distribution and his likelihood of challenging or withdrawing. We can then simultaneously vary the exaggeration practiced by the Signaller and that anticipated by the Receiver over a range of values and compare the expected payoffs for each participant at adjacent points in the range.

The analysis is complicated, however, by the fact that variation in the exaggeration factor has a much larger effect on the expected payoff at low levels of fighting ability (Fig. 3). If the effects of a single value of $\mathrm{x}$ or $\mathrm{y}$ are averaged across all levels of $\mathrm{V}$, the pattern for $\mathrm{V}=1$ or 2 will dominate the results. What we require is an expression for an "exaggeration strategy," a function that corrects for the differential effects of $V$ on the range of payoff values. Each strategy level will then represent not a single exaggeration factor, but an array of factors, one for each level of fighting ability.

A standard means of controlling for the influence of an auxiliary variable is multivariate regression. In this case, the regression is performed on the data in Fig. 4 , in which the optimal exaggeration factor appears to vary log-linearly with 
$\mathrm{C}$ for each value of $\mathrm{V}_{\mathrm{S}}$. If $\log \left(\mathrm{x}_{\mathrm{opt}}\right)$ is subjected to analysis of covariance, we can extract a function that relates optimal exaggeration rate to $\mathrm{C}$, controlling for $\mathrm{V}$. The resulting model provides a different intercept for each value of $\mathrm{V}$, ranging from 2.49 to -1.18 for progressively larger $\mathrm{V}$, but a constant slope of 0.187 . Using this relationship as an underlying rule, we can generate a family of exaggeration strategies, $S$, where the exaggeration factor to be used at each level of $\mathrm{V}$ is computed from $\log [\mathrm{x}(\mathrm{V})]=.187 \mathrm{~S}+\mathrm{f}(\mathrm{V})$, where $\mathrm{f}$ is the array of intercepts from the analysis of covariance. The mean expected payoff from $\mathrm{S}$ across all values of $\mathrm{V}$ is, thus, an unbiased indication of the effects of a particular exaggeration strategy.

The results of independent strategic decisions are most readily displayed in a two-dimensional vector diagram, in which the magnitude and direction of payoff differences along the Signaller and Receiver axes describe the direction of movement of the system under unconstrained conditions. If, for example, the system is at some specified point, $\left(S_{R}, S_{S}\right)$, and the expectation of the Receiver, $E_{R}$, can be increased by increasing the exaggeration he assumes the Signaller to be practicing (i.e. $E_{R}\left[S_{R}, S_{S}\right]<E_{R}\left[S_{R}+\delta, S_{S}\right]$ ), then the relative payoffs of the Receiver will generate a vector parallel to the Receiver axis, in a positive direction, with a length proportionate to the difference between the Receiver's expectations at adjacent strategies. Similarly, differences in Signaller payoff expectations will generate vectors parallel to the Signaller axis. For any point, $\left(S_{R}, S_{S}\right)$, the two vectors operate simultaneously, yielding a resultant that describes the direction and velocity of movement of the system within the strategy space.

The consequence of applying this computation to a wide variety of possible strategy combinations is the generation of vector diagrams similar to those used to describe predator/prey systems in community ecology (ROUGHGARDEN 1979). If the communication system is stable, the two participants, by adjusting their respective exaggeration strategies to maximize their own expected payoffs, should converge to a single common value. If, on the contrary, it is unstable, as predicted by the Natural Superiority of Deceit, both exaggeration strategies should quickly become fixed at the high end of the scale. Vector diagrams were generated using a range of $S$ values from -5 to +5 for three different levels of $C$ (Fig. 5). In each case, a unique, central equilibrium point is evident.

\section{Discussion}

The numerical simulation of our model of animal conflict strongly supports the hypothesis of an optimal level of deceit in aggressive communication. Although there is a clear advantage to exaggerating one's fighting ability to dissuade other animals from escalating the conflict to potentially damaging levels, displays must retain a sufficient level of information to convince the opposing party to attend to them. The postulated Natural Superiority of Deceit is, in these terms, limited, and we can conceive of animal displays as containing a mixture of correct and misleading information.

Provided that both participants adhere to an ability-compensated rule for generating exaggeration strategies, moreover, the information content of the 

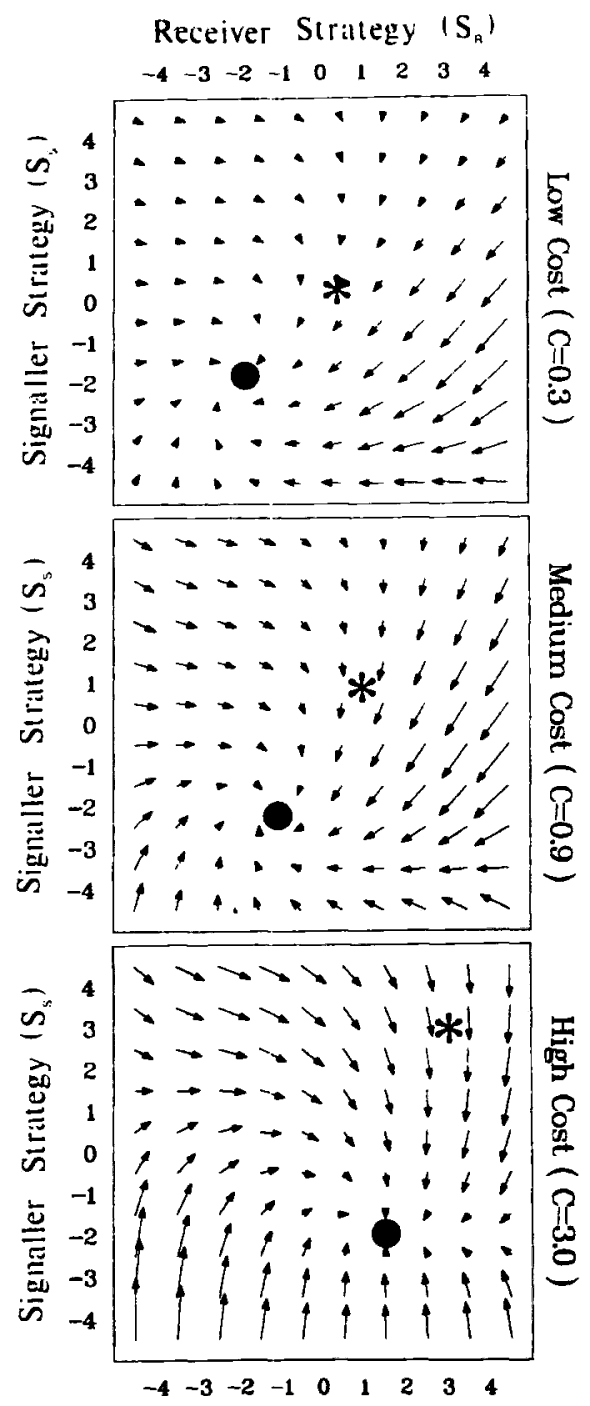

Fig. 5: Vector diagrams of the payoff relationships for Receiver and Signaller, as a function of exaggeration strategy $\left(S_{R}\right.$ or $\left.S_{S}\right)$, for three different levels of cost of challenging (C). Exaggeration strategies control for the differential effects of Signaller fighting ability and increase from -5 to +5 with increasing levels of exaggeration. The vectors represent the resultants of individual pairwise comparisons of expected payoffs for adjacent strategies for both participants. Vector length is scaled such that it displays a constant maximum value across the three plots. Its length within a plot indicates the relative strength of the tendency of the system to move in the specified direction. Equilibrium points, located by eye, are displayed with filled circles; asterisks indicate strategies adopted with complete knowledge

Receiver Strategy $\left(S_{\mathrm{p}}\right)$

display should be expected to converge on an equilibrium value, even in the absence of perfect knowledge of which strategy the other animal is pursuing. The common generating rule is not as restrictive a limitation as one might imagine: it amounts to constraining the animals to behave consistently across the possible range of concealed abilities. Such limiting rules are a common feature of game theoretic analyses (MAYNARD SMITH 1984).

As in a predator-prey system, the equilibrium will be unstable: the Signaller can always better his payoff by doing something other than what the Receiver expects. What maintains the equilibrium is that any change in exaggeration 
strategy generates opposing tendencies in the other individual's expectations that drive the system back toward its initial conditions.

"Evolutionary stability," in the strict sense of MAYNARD SMITH (1974), entails that one strategy or mix of strategies, when adopted by an entire population, will be superior to all competing alternatives. The model we have used to illustrate optimal deceit is not a population game, but rather a game of individual strategic choices. The applicability of MAYNARD SMITH's concept is, therefore, necessarily indirect. It appears, however, that in a large population of individuals, alternately playing Signaller and Receiver, the strategy choices of all participants should converge to a predictable value over time. In this loose sense, optimal deceit may be evolutionarily stable.

It is a striking feature of these results that the equilibrial value is less, at all three levels of cost of challenging, than would have been the case if the Receiver had known what exaggeration strategy was being applied (Fig. 5). This suggests that lack of information in a communicatory system may have a conservative effect. The greater the ignorance of the Receiver, the more truthful the Signaller must be if he is to be successful in manipulating the Receiver's behavior.

Several other considerations also point to the possibility that levels of deception may be minimized in the real world. The game theory argument hinges on the assumption that escalation to actual combat is a costly and potentially damaging event for both sides. Escalation is not irreversible, however. Attacks can often be evaded or successfully defended against (GEIST 1974). Under many circumstances, attacks can be of brief duration, with both combatants quickly withdrawing and resuming aggressive displays. The cost of such "probing" bouts of combat could be fairly negligible, in which case, the optimal exaggeration levels would be reduced (Fig. 4). VAN RHIJN (1980; van RHIJN \& VODEGEL 1980) has pointed out, in addition, that the possibility of repeated probing battles between individuals who can recognize and remember their opponents on subsequent occasions makes deception extremely difficult to sustain. It appears, therefore, that although optimal deceit is a real theoretical possibility, it may only be realized in nature in circumstances in which an individual's fighting ability fluctuates significantly over time (CALDWELL 1986).

\section{Approaches for Further Research}

The simplest prediction of the optimal deceit model that can readily be applied to real-world behavior is that some exaggeration ought to be detectable in aggressive displays, in that victories based on display alone should bear a looser relationship to the relative fighting ability of the two participants than those that result from escalated combat. One approach to testing this hypothesis would make use of staged encounters, analyzing their results with logistic regression (Cox 1970; BARLOW 1983).

Using a species in which escalation was commonly involved in aggressive encounters, but which at least occasionally resolved conflicts by display alone, one would plot the probability of victory against some composite indicator of actual fighting ability. BARLOw et al. (1986) have recently published experiments 


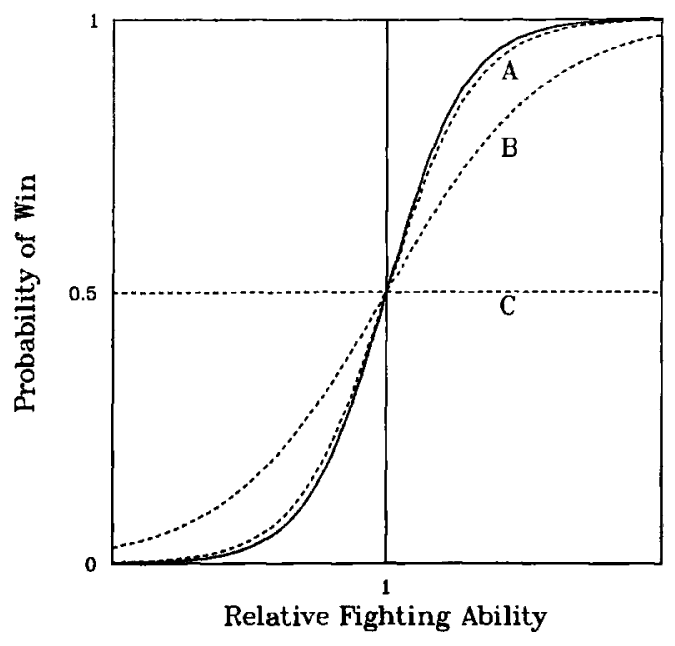

Fig. 6: Hypothetical relationships between fighting ability and the probability of winning an aggressive encounter for three possible experimental outcomes. In each case, the solid sigmoidal curve represents conflicts that were resolved by escalation while the dashed curves represent conflic resolved by display alone. Case A: th logistic regression coefficients are signifi cantly positive for both solid and dashe curves, but they do not differ significantl. from one another (evidence of truthful dis: plays). Case B: both coefficients are signifi cantly positive and different from on another (evidence of partially informativ displays). Case C: coefficient for soli curve is significantly positive, while tha for dashed curve does not differ from zert (evidence of noninformative displays)

directed to this type of analysis. To test for the occurrence of deceit, data woul be plotted separately for contests that were resolved by display alone and fo. those that were escalated to physical combat. Hypothetical curves for thre possible outcomes of this experiment are shown in Fig. 6 .

Assuming that the measure of fighting ability used is adequate, the curve fo escalated conflicts (solid line in Fig. 6) should have a significantly positiv regression coefficient, implying that animals that are better fighters tend to wi escalated conflicts. The differences among the three outcomes lie in their predic tions for the display-only curve (dashed lines in Fig. 6). If aggressive displays ar essentially noninformative, the probability of winning a display-only conflic should be independent of relative fighting ability (Line C in Fig. 6), and th logistic regression coefficient should not differ significantly from zero. If display are fully as informative of fighting ability as an animal's actual performance $i$ combat, the escalated and display-only curves should both have positive coeffi cients, but should not differ significantly from one another (Line A in Fig. 6) Evidence for exaggeration would fall between these two extremes: the regressio coefficient for both curves should be significantly positive, but that for th display-only results should be significantly smaller, indicating that fighting abilit. is less strongly related to success in a purely conventional conflict (Line B i Fig. 6).

\section{Appendix A: The Expectation from Three Simple Strategies}

\section{Expectation from Veracity}

There are 100 possible combinations of concealed ability values, of which th Receiver would win on 45 in a showdown. If the Signaller displays truthfully, th Receiver will always withdraw when he would lose on a challenge and alway challenge when his V level is higher. The expected payoff to the Signaller from policy of strict honesty is, thus, $\mathrm{E}_{\mathrm{S}}=0.01(55 \mathrm{~W}-45 \mathrm{~L}-45 \mathrm{C})$, while that to th Receiver is $\mathrm{E}_{\mathrm{R}}=0.01(45 \mathrm{~W}-55 \mathrm{~L}-45 \mathrm{C})$. 


\section{Expectation from $10 \%$ Deceit}

Consider that $10 \%$ of the contests the Signaller would otherwise have lost might be turned to wins by exaggeration. Then, $E_{S}=0.01$ $(59.5 \mathrm{~W}-40.5 \mathrm{~L}-40.5 \mathrm{C})$ and $\mathrm{E}_{\mathrm{R}}=0.01(40.5 \mathrm{~W}-59.5 \mathrm{~L}-40.5 \mathrm{C})$.

\section{Expectation from Noninformation}

The consequences of noninformation are more complicated, since they reflect the Receiver's evaluation of the a priori odds. If the probability that the Signaller would win on a challenge is $P\{w\}=P\left\{V_{S} \geq V_{R}\right\}$, and if the probability distribution of $V_{S}$ is assumed to be uniform, then $P\{w\}=\left(11-V_{R}\right) / 10$. The expected payoff to the Receiver on a challenge is

$$
\mathrm{P}\{\mathrm{w}\}(-\mathrm{L}-\mathrm{C})+(1-\mathrm{P}\{\mathrm{w}\})(\mathrm{W}-\mathrm{C}) .
$$

By employing a Bayes criterion, the Receiver should challenge whenever this is greater than $-\mathrm{L}$ and withdraw otherwise (CHERNOFF \& MOsEs 1959). This defines a critical value of $P\{w\}$ for the Receiver's decision, $\mathbf{w}_{C}$ :

$$
\begin{aligned}
& \mathrm{P}\{\mathrm{w}\}(-\mathrm{L}-\mathrm{C})+(1-\mathrm{P}\{\mathrm{w}\})(\mathrm{W}-\mathrm{C})<-\mathrm{L} \\
& \mathrm{P}\{\mathrm{w}\}(\mathrm{L}+\mathrm{W})<\mathrm{L}+\mathrm{W}-\mathrm{C} \\
& \mathrm{P}\{\mathrm{w}\}<\frac{\mathrm{L}+\mathrm{W}-\mathrm{C}}{\mathrm{L}+\mathrm{W}} \equiv \mathrm{w}_{\mathrm{C}}
\end{aligned}
$$

Since the Receiver possesses only a knowledge of the value of his own concealed ability $, V_{R}, w_{C}$ translates directly into a critical value, $V_{C}$, which is the largest integer less than or equal to $(\mathrm{L}+\mathrm{W}+10 \mathrm{C}) /(\mathrm{L}+\mathrm{W})$. In the noninformation strategy, the Receiver will attack when $V_{R}>V_{C}$ and withdraw otherwise.

If the probability that the Receiver will challenge the Signaller is $P\{c\}$, then the probability of a withdrawal is $(1-\mathrm{P}\{\mathrm{c}\})$. This must be equivalent, by the reasoning above, to $V_{C} / 10$, so the Receiver will challenge on $10\left(10-V_{C}\right)$ of the 100 possible ability combinations. On the occasion of a challenge, the Signaller will have a concealed ability of $V_{C}$ or less $V_{C} / 10$ of the time and will lose in the showdown. This will occur in $10\left(10-V_{C}\right)\left(V_{C} / 10\right)=V_{C}\left(10-V_{C}\right)$ of the challenges. The number of possible challenges remaining is $10\left(10-V_{C}\right)\left(1-V_{C} / 10\right)=$ $\left(10-V_{C}\right)^{2}$. Of these, the Signaller will win $\left(10-V_{C}\right)$ by tieing the Receiver and will better the Receiver on half of the remainder, or $\left[\left(10-V_{C}\right)^{2}-\left(10-V_{C}\right)\right] / 2$. The probability that the Signaller will win on a challenge is, thus:

$$
P\{w \mid c\}=\frac{\left(10-V_{C}\right)^{2}-\left(10-V_{C}\right)+2\left(10-V_{C}\right)}{20\left(10-V_{C}\right)}=\frac{11-V_{C}}{20}
$$

The expected payoff to the Signaller of a noninformation strategy is:

$$
\mathrm{E}_{\mathrm{S}}=(1-\mathrm{P}\{\mathrm{c}\}) \mathrm{W}+\mathrm{P}\{\mathrm{c}\}[\mathrm{P}\{\mathrm{w} \mid \mathrm{c}\}(\mathrm{W}-\mathrm{C})+(1-\mathrm{P}\{\mathrm{w} \mid \mathrm{c}\})(-\mathrm{L}-\mathrm{C})]
$$

Substituting,

$$
E_{S}=\frac{V_{C} W}{10}+\frac{10-V_{C}}{10}\left[\frac{11-V_{C}}{20}(W-C)+\frac{9+V_{C}}{20}(-L-C)\right]
$$


Collecting terms,

$$
\mathrm{E}_{\mathrm{S}}=0.05\left\{11 \mathrm{~W}-9 \mathrm{~L}-20 \mathrm{C}+\frac{\mathrm{V}_{\mathrm{C}}}{10}\left[(\mathrm{~L}+\mathrm{W})\left(\mathrm{V}_{\mathrm{c}}-1\right)+20 \mathrm{C}\right]\right\}
$$

A similar reasoning produces

$$
\mathrm{E}_{\mathrm{R}}=0.05\left\{9 \mathrm{~W}-11 \mathrm{~L}-20 \mathrm{C}+\frac{\mathrm{V}_{\mathrm{C}}}{10}\left[(\mathrm{~L}+\mathrm{W})\left(1-\mathrm{V}_{\mathrm{C}}\right)+20 \mathrm{C}\right]\right\}
$$

An idea of the relative effects of these three strategies can now be obtained $b$ evaluating $E_{S}$ and $E_{R}$ for specific values of the payoff parameters.

\section{Appendix B: The Simulation Algorithm}

\section{The Strategy of the Signaller}

I have assumed that the degree of exaggeration is distributed as a Poisso variate. If the Signaller has a concealed ability of $V_{S}$, the probability of a display $\mathrm{V}^{*}$ is a function of the difference between the display and the true ability val $\left(D=V^{*}-V_{S}\right)$. The generating parameter, $x$, represents the expected value this disparity and will be termed the "exaggeration factor." For $V^{*}<10$,

$$
P\left\{V^{*} \mid V_{s}\right\}= \begin{cases}0 & D<0 \\ e^{-x} \frac{x^{D}}{D !} & D \geq 0\end{cases}
$$

where $\mathrm{x}$ is rational and nonnegative. Since 10 is the upper limit of conceale ability, $\mathrm{P}\left\{\mathrm{V}^{*}=10\right\}$ consists of the pooled residual probability of the upper tail the function:

$$
\mathrm{P}\left\{\mathrm{V}^{*}=10 \mid \mathrm{V}_{\mathrm{S}}\right\}=1-\sum_{\mathrm{i}=1}^{\mathrm{i}=9} \mathrm{P}\left\{\mathrm{i} \mathrm{V}_{\mathrm{S}}\right\}
$$

\section{The Response of the Receiver}

From a knowledge of the exaggeration factor being employed, the Receiv constructs a retrospective probability distribution of the true value of $t$ Signaller's concealed abilities:

$$
P\left\{V_{S} \mid V^{*}\right\}=\frac{P\left\{V^{*} \mid V_{S}\right\}}{\sum_{i=1}^{i=10} P\left\{V^{*} \mid i\right\}}
$$

Given the retrospective distribution and a knowledge of his own conceale ability, $V_{R}$, the Receiver can then estimate the probability that the Signaller woul win if challenged, $P\{w\}$, as the sum of retrospective probabilities of ability leve greater than or equal to $V_{R}$ :

$$
P\{w\}=\sum_{i=v_{R}}^{i=10} P\left\{i l V^{*}\right\}
$$


From a knowledge of $P\{w\}$, the Receiver could then apply a Bayes strategy, as described in Appendix A, and challenge whenever his expected payoff on a challenge was greater than $-\mathrm{L}$. This defines $\mathrm{w}_{C}$, the critical value of $P\{w\}$ for the Receiver's decision. Aside from its methodological simplicity, however, there is no good reason to adopt a rigid Bayes criterion. The use of a Bayes criterion postulates a precision in the Receiver's knowledge of the underlying process that is wholly unrealistic. When the true values of $x, V_{S}$, and $V_{R}$ are subject to variance in estimation, as they would be in the real world, the probability of challenging or withdrawing will never be 1 or 0 .

A less stringent assumption is a probabilistic relationship between $\mathrm{P}\{\mathrm{w}\}$ and the probability of a challenge, $P\{c\}$, with $P\{c\}$ varying smoothly, rather than discontinuously, between 0 and 1 . At $P\{w\}=w_{C}$, the options of challenging and withdrawing are exactly equal in their expected payoffs. We would, thus, expect the Receiver to challenge, under these circumstances, $50 \%$ of the time. As $\mathrm{P}\{\mathrm{w}\}$ increases from the critical point, $\mathrm{P}\{\mathrm{c}\}$ should decrease, approaching 0 when $\mathrm{P}\{\mathrm{w}\}=1$; as $\mathrm{P}\{\mathrm{w}\}$ decreases, $\mathrm{P}\{\mathrm{c}\}$ should increase, becoming 1 when $P\{w\}=0$. Between these predetermined points, the transformation function should be smooth and monotonic. Any function possessing these attributes would serve the purpose, but aesthetics dictate that it also be symmetrical around $\mathrm{P}\{\mathbf{w}\}=\mathrm{P}\{\mathrm{c}\}$.

One curve that fits these constraints is a quadratic:

$$
\mathrm{P}\{\mathrm{c}\}^{2}+\mathrm{a} \mathrm{P}\{\mathrm{c}\} \mathrm{P}\{\mathrm{w}\}+\mathrm{P}\{\mathrm{w}\}^{2}=1
$$

Since we know that the curve must pass through $\left(1 / 2, \mathrm{w}_{C}\right)$, we can derive

$$
\begin{aligned}
& \mathrm{w}_{\mathrm{C}}^{2}+\mathrm{a} \frac{\mathrm{w}_{\mathrm{C}}}{2}+\frac{1}{4}=1, \\
& \text { or } \mathrm{a}=\frac{3}{2 \mathrm{w}_{\mathrm{C}}}-2 \mathrm{w}_{\mathrm{C}}
\end{aligned}
$$

For values of $\mathrm{C}<(\mathrm{L}+\mathrm{W}) / 2$, the quadratic transformation function is ill-conditioned, generating probabilities greater than 1 . In these cases, therefore, the inverse function was used:

$$
(1-P\{w\})^{2}+b(1-P\{w\})(1-P\{c\})+(1-P\{c\})=1 .
$$

When compared with the results of using a Bayes criterion, this transformation smooths the expected value curves and enhances our ability to detect optima, but it does not alter the essentially deterministic nature of the Receiver's behavior. Given the payoff matrix, the exaggeration factor, and the Signaller's display, the probability that the Receiver will challenge or withdraw is uniquely specified.

\section{Literature Cited}

ANDERSSON, M., 1980: Why are there so many threat displays? J. Theor. Biol. 86, 773-781.

BARLOW, G. W., 1983: Do gold Midas cichlid fish win fights because of their color, or because they lack normal coloration? A logistic solution. Behav. Ecol. Sociobiol. 13, 197-204.

- - W. Rogers \& N. Fraley, 1986: Do Midas cichlids win through prowess or daring? It depends. Behav. Ecol. Sociobiol. 19, 1-8. 
- - \& T. E. Rowell, 1984: The contribution of game theory to animal behavior. Behav. Brain Sci 7, 101-103.

BOND, A. B., 1989: Towards a resolution of the paradox of aggressive displays: II. Behaviora efference and the communication of intentions. Ethology, in press.

CALDWELL, R. L., 1986: The deceptive use of reputation by stomatopods. In: Deception: Perpectives on Human and Nonhuman Deceit. (MrTchell, R. W., \& N. S. Thompson, eds.) SUNY Press, Albany, pp. 129-145.

CARYL, P. G., 1979: Communication by agonistic displays: what can games theory contribute to ethology? Behaviour 68, 136-169.

Chernoff, H., \& L. E. Moses, 1959: Decision Theory. Wiley, New York.

Cox, D. R., 1970: Analysis of Binary Data. Chapman \& Hall, London.

DAWKINS, R., \& J. R. KREBS, 1978: Animal signals: information or manipulation? In: Behavioura Ecology. (KREBS, J. R., \& N. B. DAvIES, eds.) Blackwell, Oxford, pp. 282-309.

GEIST, V., 1974: On fighting strategies in animal combat. Nature 250, 354.

Hammerstein, P., 1981: The role of asymmetries in animal conflicts. Anim. Behav. 29, 193-205.

- _, \& G. A. PARKER, 1982: The asymmetric war of attrition. J. Theor. Biol. 96, 647-682.

HINDE, R. A., 1981: Animal signals: ethological and games-theory approaches are not incompatible Anim. Behav. 29, 535-542.

MAYNARD SMITH, J., 1972: Game theory and the evolution of fighting. In: On Evolution. (MAYNARI SMITH, J., ed.) Edinburgh Univ. Press, Edinburgh, pp. 8-28.

- - 1974: The theory of games and the evolution of animal conflicts. J. Theor. Biol. 47, 209-221

- - 1982: Evolution and the Theory of Games. Cambridge Univ. Press, Cambridge.

- -, 1984: Game theory and the evolution of behaviour. Behav. Brain Sci. 7, 95-101.

- —, \& G. A. PARKER, 1976: The logic of asymmetric contests. Anim. Behav. 24, 159-175.

Mitchell, R. W., 1986: A framework for discussing deception. In: Deception: Perspectives o1 Human and Nonhuman Deceit. (MrTChel., R. W., \& N. S. ThOMPSON, eds.) SUNY Press Albany, pp. 3-40.

MOYNIHAN, M., 1982: Why is lying about intentions rare during some kinds of contests? J. Theon Biol. 97, 7-12.

PARKer, G. A., 1974: Assessment strategy and the evolution of fighting behaviour. J. Theor. Biol. 47 223-243.

- -, \& D. I. RUBENSTEIN, 1981: Role assessment, reserve strategy, and acquisition of informatio: in asymmetric animal conflicts. Anim. Behav. 29, 221-240.

Roughgarden, J., 1979: Theory of Population Genetics and Evolutionary Ecology: an Introduo tion. Macmillan Press, New York.

SMITH, W. J., 1977: The Behavior of Communicating. Harvard Univ. Press, Cambridge.

- - 1986: An "informational" perspective on manipulation. In: Deception: Perspectives of Human and Nonhuman Deceit. (MrTChell, R. W., \& N. S. THOMPSON, eds.) SUNY Press Albany, pp. 71-86.

TINBERgen, N., 1951: The Study of Instinct. Clarendon Press, Oxford.

- - 1959: Comparative studies of the behaviour of gulls (Laridae): a progress report. Behaviour 15 $1-70$.

VAN RHJN, J. G., 1980: Communication by agonistic displays: a discussion. Behaviour 74, 284-293

- - \& R. VODEGEL, 1980: Being honest about one's intentions: an evolutionary stable strategy fo animal conflicts. J. Theor. Biol. 85, 623-641.

ZaHAVI, A., 1977: Reliability in communication systems and the evolution of altruism. In: Evolutionary Ecology. (STONehouse, B., \& C. Perrins, eds.) Univ Park Press, Baltimore pp. 253-259.

- - 1981: The lateral display of fishes: bluff or honesty in signalling? Behav. Anal. Lett. 1 233-235.

Author's address: Alan B. Bond, San Diego Natural History Museum, Balboa Park. P.O Box 1390, San Diego, California 92112, U.S.A. 